\title{
Région de Beaulieu-sur-Loire
}

$\mathrm{n}^{\circ} 068575$

Frédéric Bordeau

\section{(2) OpenEdition}

\section{Journals}

Édition électronique

URL : http://journals.openedition.org/adlfi/13883

ISSN : 2114-0502

Éditeur

Ministère de la culture

Référence électronique

Frédéric Bordeau, «Région de Beaulieu-sur-Loire », ADLFI. Archéologie de la France - Informations [En ligne], Centre, mis en ligne le 19 novembre 2014, consulté le 22 avril 2019. URL : http:// journals.openedition.org/adlfi/13883

Ce document a été généré automatiquement le 22 avril 2019

(C) Ministère de la Culture et de la Communication, CNRS 


\title{
Région de Beaulieu-sur-Loire
}

$n^{\circ} 068575$

\author{
Frédéric Bordeau
}

Lien Atlas (MCC) :

http://atlas.patrimoines.culture.fr/atlas/trunk/index.php?

ap_theme=DOM_2.01.02\&ap_bbox $=2.732 ; 47.494 ; 2.875 ; 47.581$

1 Nous avons survolé principalement la commune de Beaulieu et le quart sud-est de la commune de Châtillon, notre but étant d'inventorier toute trace de présence humaine dans cette zone et de compléter les données des prospections pédestres, notamment pour la période gallo-romaine. Nous avons utilisé un ULM pendulaire biplace, piloté par Alain Feuillette. Les vols ont été effectués entre le 5 juin et le 5 juillet. La météo capricieuse de ce mois de juin a réduit notre temps total de vol à environ 3 heures, par tranches de 25 minutes en moyenne.

Les nombreux sites à fondations connus par les prospections de surface sont restés muets, tandis que plusieurs enclos fossoyés ont été découverts. La majorité des traces observées sont dues à des indices phytographiques sur céréales. Plusieurs sites découverts en 1996 ont été complétés et 3 nouveaux sites ont été enregistrés. Les mottes féodales découvertes l'année précédente étaient visibles et les clichés de cette année permettent leur redressement sur fond cadastral. De nouveaux clichés ont été réalisés sur les 2 voies secondaires romaines se croisant au lieu-dit la Prebenderie ; leur liaison avec les ferriers du Puits d'Havenat se confirme. Un petit diverticule menant au grand ferrier du puits d'Havenat nord était visible. Des semis de fosses comparables à ceux observés en 1996 sur la commune de Châtillon étaient visibles en grand nombre, notamment entre le hameau de Chanoy et la zone industrielle de Châtillon. Ces fosses, révélées par des micro-reliefs dans les céréales, se situent toujours à proximité des voies. L'hypothèse d'un puits d'extraction du minerai de fer semble probable étant donné les quantités de fosses observées.

3 Sur la commune de Beaulieu, un enclos quadrangulaire présentant une entrée orientée au nord-ouest a été découvert, et de nombreux indices gallo-romains ont été observés au sol 
(tegulae, pierres calcaires et céramiques communes). Il s'agit probablement d'un établissement rural d'époque romaine, mais l'enclos observé pourrait témoigner d'un état antérieur (ferme indigène ?). Cette structure est située à quelques centaines de mètres à peine de la nécropole mérovingienne de Maimbray. Sur la même commune, 2 enclos quadrangulaires aux angles arrondis ont été découverts, et près de l'un d'eux, 2 enclos, probablement funéraires, étaient visibles. Le plus grand, de forme ovale, recèle 2 fosses ; le second, de plan subcirculaire semble également contenir une fosse. Les 2 enclos quadrangulaires ont des caractéristiques similaires : leurs schémas d'implantation sont semblables et leurs caractéristiques typologiques les apparentent au groupe des Viereckschanzen. Ces 2 enclos sont espacés de $2 \mathrm{~km}$ et un ancien chemin, en partie remembré, semble relier les 2 sites. La prospection au sol n'ayant pas livré d'éléments de datation certains, nous en sommes réduits aux suppositions et aux hypothèses habituellement proposées pour ce genre de sites. Ces deux sites constituent à notre connaissance les premières découvertes de ce type dans le sud du Loiret et les premiers indices protohistoriques de notre canton.

4 En conclusion, la zone étudiée présente, sur une surface restreinte, une concentration de sites gallo-romains remarquable et pourrait constituer un terrain d'étude très intéressant pour la fin de l'indépendance gauloise et le processus de romanisation.

\section{INDEX}

Index géographique : Centre, Loiret (45), Beaulieu-sur-Loire

operation Prospection aérienne (PA)

Mots-clés : enclos, établissement, fosse 